\title{
Angiogenic Activity of Sera from Interstitial Lung Disease Patients in Relation to Pulmonary Function
}

\author{
T. M. Zielonka ${ }^{1}$, U. Demkow ${ }^{2}$, E. Radzikowska ${ }^{3}$, B. Bialas ${ }^{3}$, M. Filewska ${ }^{3}$, K. Zycinska ${ }^{1}$, M. H. Obrowski ${ }^{1}$, \\ J. Kowalski ${ }^{3}$, K. A. Wardyn ${ }^{1}$, E. Skopinska-Rozewska ${ }^{4}$ \\ ${ }^{1}$ Department of Family Medicine, Warsaw Medical University, Warsaw, Poland; \\ ${ }^{2}$ Department of Laboratory Diagnostics and Clinical Immunology of the Developmental Age, Warsaw Medical University, Warsaw, Poland; \\ ${ }^{3}$ Institute of Tuberculosis and Lung Diseases, Warsaw, Poland; \\ ${ }^{4}$ Department of Pathology, Biostructure Center, Warsaw Medical University, Warsaw, Poland
}

\begin{abstract}
Objective: Chronic inflammation and fibrosis are characteristic of interstitial lung diseases (ILD) and are accompanied by neovascularisation. The aim of this study was to examine the relationship between the angiogenic activity of sera from ILD patients and pulmonary function tests.

Material and methods: Serum samples were obtained from 225 ILD patients: 83 with sarcoidosis, 31 with idiopathic pulmonary fibrosis, 29 with extrinsic allergic alveolitis, 16 with collagen vascular diseases, 13 with scleroderma with pulmonary manifestations (SCL), 14 with Wegener's granulomatosis (WG), 12 with silicosis, 12 with pulmonary Langerhans cells histiocytosis, 10 with drug-induced pulmonary fibrosis, 5 with cryptogenic organizing pneumonia, and 36 healthy volunteers. An animal model of leukocyte induced angiogenesis assay was used as an angiogenic test. In all patients spirometry, whole body plethysmography, static lung compliance, and single breath diffusing capacity of the lungs for carbon monoxide $\left(\mathrm{DL}_{\mathrm{CO}}\right)$ were performed.

Results: The angiogenic properties of sera from ILD differed, depending on the disease. In the examined ILD, the most important functional disturbances were decreases in static compliance and DLco. The correlation between $\mathrm{DL}_{\mathrm{CO}}$ and angiogenic activity of sera was observed $(\mathrm{P}<0.05)$.

Conclusions: The data show that sera from ILD patients constitute a source of mediators modulating angiogenesis. Angiogenic activity of sera of ILD patients is related to $\mathrm{DL}_{\mathrm{CO}}$.
\end{abstract}

Key words: angiogenesis, interstitial lung diseases, lung function tests, diffusing capacity

\section{INTRODUCTION}

Interstitial lung diseases (ILD) constitute a large group of disorders characterized by various etiology and pathogenesis [1]. Inflammation and fibrosis are the most important processes in the course of ILDprovoked disturbances in gas exchange and hypoxia [2]. Chronic inflammation and hypoxia are strong stimuli for neovascularisation [3]. Angiogenesis participates in the pathogenesis of idiopathic pulmonary fibrosis (IPF) $[4,5]$ and probably also in other ILD [6, 7]. However, the role of angiogenesis in the pathogenesis of ILD is unclear. Aberrant angiogenesis and defective epithelial repair are key features of IPF [5]. Ebina et al [8] have demonstrated an increase in the density of capillaries and a decrease in lung vascularisation in IPF. Data concerning the role of neoangiogenesis in the pathogenesis of ILD have created a target for new drugs. Thalidomide, a strong antiangiogenic drug has been used successfully in some cases of ILD [9]. Previously, we described a modulation of angiogenesis by sera from patients with ILD and its relation to clinical symptoms and radiological changes [10]. Little is known about the extent of neovascularisation in ILD in relation to pulmonary function. The aim of this study was to evaluate the angiogenic activity of sera from ILD patients in relation to lung function.

\section{Material AND Methods}

\section{PATIENTS}

The protocol of this study was approved by the local Ethics Committees for both human and animal research. The study population consisted of 225 ILD patients (Table 1): 122 men and 103 women (mean age $47 \pm 15)$. The majority of them (159) had never smoked tobacco. Blood samples were taken from patients before treatment with steroids or immunosuppressants. The diagnosis of ILD was based on clinical, radiological, functional, serological, BAL, and pathological findings according to the previously described criteria [10]. The group of collagen or vascular diseases with pulmonary manifestations, confirmed by high resolution computed tomography, consisted of 14 patients with WG, 13 with SCL, 7 with rheumatoid arthritis, 4 with systemic lupus erythematosus, 2 with dermatomyositis, 2 with a mixed connective tissue disease, and 1 patient with psoriatic arthritis. For the control purpose, we used sera from 36 healthy volunteers recruited from our medical staff previously characterized [10]. 
Table 1. Characteristics of the examined number of patients in disease-stratified groups.

\begin{tabular}{ccccc}
\hline & No. of subjects & Age $(\mathrm{yr})$ & Female/Male & Smokers/non-smokers \\
\hline Sarcoidosis & 83 & $40 \pm 12$ & $35 / 48$ & $20 / 63$ \\
IPF & 31 & $61 \pm 12$ & $14 / 17$ & $9 / 22$ \\
EAA & 29 & $47 \pm 16$ & $13 / 16$ & $8 / 21$ \\
CVD & 16 & $55 \pm 11$ & $7 / 9$ & $4 / 12$ \\
SCL & 13 & $51 \pm 12$ & $11 / 2$ & $1 / 12$ \\
WG & 14 & $49 \pm 18$ & $12 / 2$ & $3 / 11$ \\
PLH & 12 & $37 \pm 13$ & $4 / 8$ & $12 / 0$ \\
Silicosis & 12 & $43 \pm 9$ & $1 / 11$ & $8 / 4$ \\
DIPF & 10 & $63 \pm 11$ & $3 / 7$ & $1 / 9$ \\
COP & 5 & $58 \pm 8$ & $3 / 2$ & $4 / 32$ \\
Healthy volunteers & 36 & $39 \pm 11$ & $22 / 14$ & \\
\hline
\end{tabular}

IPF - idiopathic pulmonary fibrosis, EAA - extrinsic allergic alveolitis, CVD - collagen vascular diseases, SCL - scleroderma, WG - Wegener's granulomatosis, PLH - pulmonary Langerhans cells histiocytosis, DIPF - drug-induced pulmonary fibrosis, COP - cryptogenic organizing pneumonia.

\section{Lung Function Tests}

In all patients, spirometry, whole body plethysmography, static lung compliance, and single-breath diffusing capacity of the lung for carbon monoxide were performed according to the ERS standards [11], using MasterLab Jaeger equipment (Hochberg, Germany). A restrictive ventilatory defect was defined as TLC lower than $80 \%$ of predicted and an obstructive one as $\mathrm{FEV}_{1} / \mathrm{FVC}<0.7$ [11]. A decrease in $\mathrm{PEF}<80 \%$ and $\mathrm{MEF}_{50}<60 \%$ and an increase in $\mathrm{RV}>120 \%$ or Raw $>130 \%$ were considered abnormal.

\section{Angiogenic ACTIVITY}

Angiogenesis was evaluated by a leukocyte-induced angiogenesis assay in an animal model described by Sidky and Auerbach [12], with some modification [10]. The Balb/c mice served as recipients of mononuclear cells (MNC) preincubated in PBS supplemented with $25 \%$ of serum from ILD patients or from healthy volunteers for one hour at $37^{\circ} \mathrm{C}$. As a control, MNC were pre-incubated only in PBS. Samples of $0.05 \mathrm{ml}$ volume containing $5 \times 10^{5} \mathrm{MNC}$ in the Parker medium were injected intradermally into mice narcotized with $3.6 \%$ chloral hydrate, using a ratio of three mice for every patient and six injections for every mouse. Three days later, angiogenic reaction was estimated by microscope (Nikon, Japan) at 6x magnification on the inner surface of the skin of each mouse. The result was evaluated blindly based on the previously described criteria [12].

\section{Statistical ANALYsis}

The results were expressed as an angiogenesis index (AI) representing the average of the mean numbers of new blood vessels after the injection of MNC pre-incubated in PBS with sera from the examined patients divided by the mean number of new blood vessels after the injection of MNC pre-incubated only in PBS. The data were presented as means \pm SD and $\mathrm{P}<0.05$ was regarded as statistically significant. Statistical evaluation was performed using a t-test and Pearson's correlation (Statistica 6 for Windows).

\section{RESULTS}

\section{Angiogenic ACtivity}

The number of newly-created vessels was highest for extrinsic allergic alveolitis (EAA) (Table 2). The mean number of new vessels formed after the injection of MNC pre-incubated with sera from collagen vascular diseases (CVD), WG, IPF, sarcoidosis, silicosis and cryptogenic organizing pneumonia (COP) patients was significantly higher than that in healthy volunteers. Sera from the patients with pulmonary Langerhans cells histiocytosis (PLH) and SCL presented antiangiogenic properties comparable with those in healthy donors and control samples with PBS.

The highest angiogenesis index was observed after incubation of MNC pre-incubated with sera from EAA (Fig. 1) and lower indices were after pre-incubation of MNC with sera from the sarcoidosis, WG, CVD, and IPF patients. The angiogenesis index of silicosis patients was higher than that of healthy donors or drug-induced pulmonary fibrosis (DIPF) patients. Sera from COP patients significantly stimulated angiogenesis compared with the sera from the PHL and SCL patients. Sera from the PLH and SCL patients strongly decreased the angiogenic capability of MNC compared with the healthy control group.

\section{Angiogenic Activity of Sera in Relation to Lung Function Tests}

In the examined ILD, the most important functional disturbances were decreases in static compliance and pulmonary oxygen diffusion measured by DL $\mathrm{CO}_{\mathrm{CO}}$ (Table 3). Cst below $80 \%$ of predictive value was observed in all groups, except the sarcoidosis and PLH patients. The obstructive ventilatory syndrome was not observed in the examined groups. 


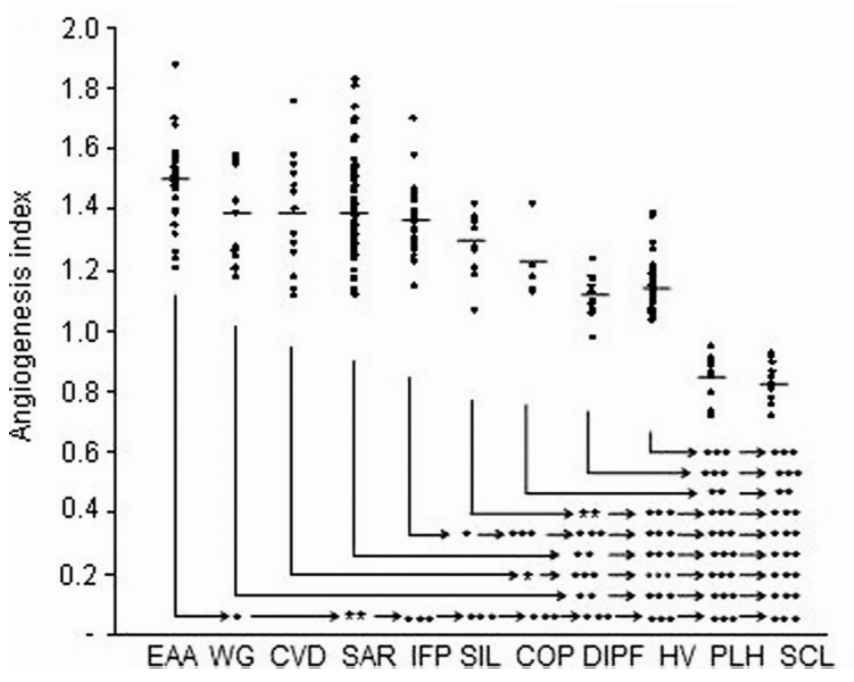

Table 2. Number of new vessels created after injection of MNC pre-incubated in sera from ILD patients, healthy volunteers, and PBS.

\begin{tabular}{ccc}
\hline & No. of vessels & P vs. PBS \\
\hline EAA & $17.5 \pm 1.3$ & 0.001 \\
WG & $16.9 \pm 1.4$ & 0.001 \\
CVD & $16.6 \pm 1.6$ & 0.001 \\
Sarcoidosis & $16.3 \pm 1.6$ & 0.001 \\
IPF & $16.2 \pm 0.9$ & 0.001 \\
Silicosis & $15.7 \pm 0.2$ & 0.001 \\
COP & $15.4 \pm 1.0$ & 0.001 \\
DIPF & $13.2 \pm 1.4$ & 0.01 \\
PBS & $12.0 \pm 1.2$ & - \\
PLH & $10.8 \pm 0.5$ & 0.001 \\
SCL & $10.4 \pm 0.7$ & 0.001 \\
Healthy volunteers & $13.7 \pm 0.9$ & 0.001
\end{tabular}

Number of vessels is given as means $\pm \mathrm{SD}$. EAA - extrinsic allergic alveolitis, WG - Wegener's granulomatosis, CVD collagen vascular diseases, IPF - idiopathic pulmonary fibrosis, COP - cryptogenic organizing pneumonia, DIPF - druginduced pulmonary fibrosis, PLH - pulmonary Langerhans cells histiocytosis, SCL - scleroderma.
Fig. 1. Angiogenesis index in examined groups after injection of MNC, pre-incubated in sera from extrinsic allergic alveolitis (EAA; $n=29$, Wegener's granulomatosis (WG; $n=14$ ), collagen vascular diseases (CVD; $\mathrm{n}=16$ ), sarcoidosis (SAR; 83), idiopathic pulmonary fibrosis (IPF; $\mathrm{n}=31$ ), silicosis (SIL; $\mathrm{n}=12$ ), cryptogenic organizing pneumonia (COP; $\mathrm{n}=$ 5), drug-induced pulmonary fibrosis (DIPF; $\mathrm{n}=10$ ), pulmonary Langerhans cells histiocytosis (PLH; 12), scleroderma $(\mathrm{SCL} ; \mathrm{n}=13)$ patients, and from healthy volunteers (HV; $\mathrm{n}=$ 36). Mean values are indicated by horizontal bars; significant differences between the groups are as follows: $* \mathrm{P}<0.05$, $* * \mathrm{P}<0.01$, and $* * * \mathrm{P}<0.001$.

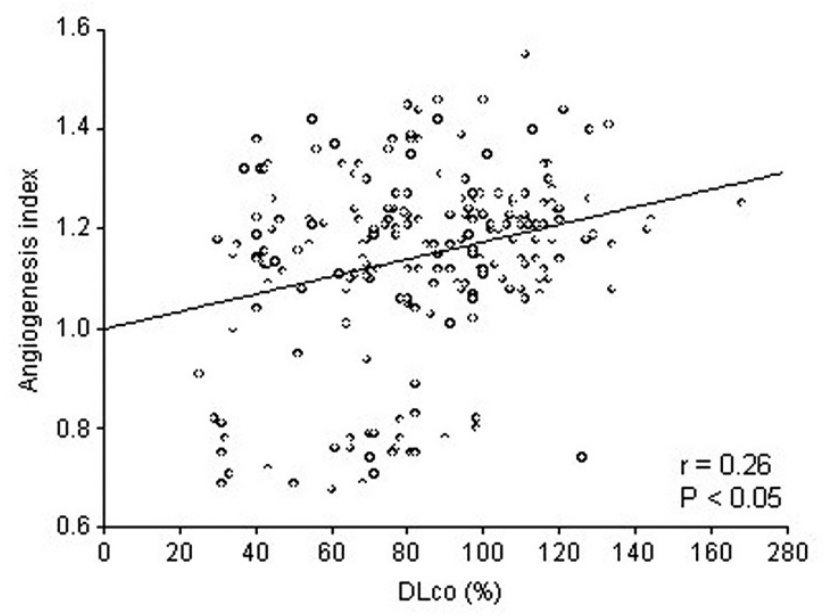

Fig. 2. Correlation between $\mathrm{DL}_{\mathrm{CO}}$ and angiogenesis index $(\mathrm{n}=216)$.

DLco significantly correlated with the angiogenesis index in the ILD patients (Fig. 2). The number of new vessels in the group of 122 patients with $\mathrm{DL}_{\mathrm{CO}}>80 \%$ (16.1 \pm 2.0$)$ was significantly higher than that in the group of 94 patients with $\mathrm{DL}_{\mathrm{CO}}<80 \%(15.0 \pm 2.8)$.

Table 3. Lung function tests.

\begin{tabular}{ccccccccc}
\hline & $\mathrm{VC}$ & $\mathrm{FEV}_{1}$ & $\mathrm{FEV}_{1} \% \mathrm{VC}$ & $\mathrm{MEF}_{50}$ & $\mathrm{Raw}$ & $\mathrm{RV}$ & $\mathrm{C}_{\text {st }}$ & DLco \\
\hline Sarcoidosis & $101 \pm 19$ & $96 \pm 19$ & $96 \pm 10$ & $81 \pm 35$ & $77 \pm 28$ & $93 \pm 20$ & $91 \pm 6$ & $102 \pm 21$ \\
IPF & $79 \pm 17$ & $83 \pm 18$ & $106 \pm 10$ & $84 \pm 34$ & $83 \pm 26$ & $73 \pm 22$ & $44 \pm 6$ & $59 \pm 8$ \\
EAA & $82 \pm 29$ & $80 \pm 26$ & $99 \pm 15$ & $80 \pm 44$ & $102 \pm 63$ & $95 \pm 35$ & $65 \pm 30$ & $78 \pm 26$ \\
SCL & $88 \pm 23$ & $84 \pm 18$ & $101 \pm 11$ & $72 \pm 21$ & $89 \pm 41$ & $93 \pm 28$ & $71 \pm 36$ & $65 \pm 28$ \\
CVD & $77 \pm 16$ & $78 \pm 14$ & $105 \pm 14$ & $70 \pm 27$ & $85 \pm 13$ & $82 \pm 23$ & $57 \pm 20$ & $68 \pm 25$ \\
WG & $98 \pm 22$ & $90 \pm 18$ & $99 \pm 19$ & $68 \pm 25$ & $91 \pm 16$ & $111 \pm 30$ & $80 \pm 22$ & $90 \pm 29$ \\
PLH & $86 \pm 14$ & $72 \pm 22$ & $85 \pm 13$ & $46 \pm 25$ & $93 \pm 19$ & $105 \pm 38$ & $81 \pm 18$ & $70 \pm 18$ \\
Silicosis & $77 \pm 25$ & $69 \pm 26$ & $86 \pm 16$ & $52 \pm 26$ & $91 \pm 26$ & $99 \pm 33$ & $74 \pm 21$ & $86 \pm 21$ \\
DIPF & $79 \pm 20$ & $81 \pm 19$ & $103 \pm 10$ & $64 \pm 20$ & $88 \pm 10$ & $82 \pm 20$ & $49 \pm 21$ & $57 \pm 21$ \\
COP & $90 \pm 32$ & $76 \pm 30$ & $85 \pm 22$ & $44 \pm 32$ & $106 \pm 16$ & $87 \pm 51$ & $64 \pm 32$ & $75 \pm 26$ \\
\hline
\end{tabular}

Data are mean percentages \pm SD. VC - vital capacity, $\mathrm{FEV}_{1}$ - forced expiratory volume in $1 \mathrm{sec}, \mathrm{MEF}_{50}-$ maximal expiratory flow at $50 \%$ of $\mathrm{FVC}$, Raw - airway resistance, $\mathrm{RV}$ - residual volume, $\mathrm{C}_{\mathrm{ST}}$ - static lung compliance, $\mathrm{DL}_{\mathrm{CO}}$ - diffusing capacity of the lungs for carbon monoxide. 


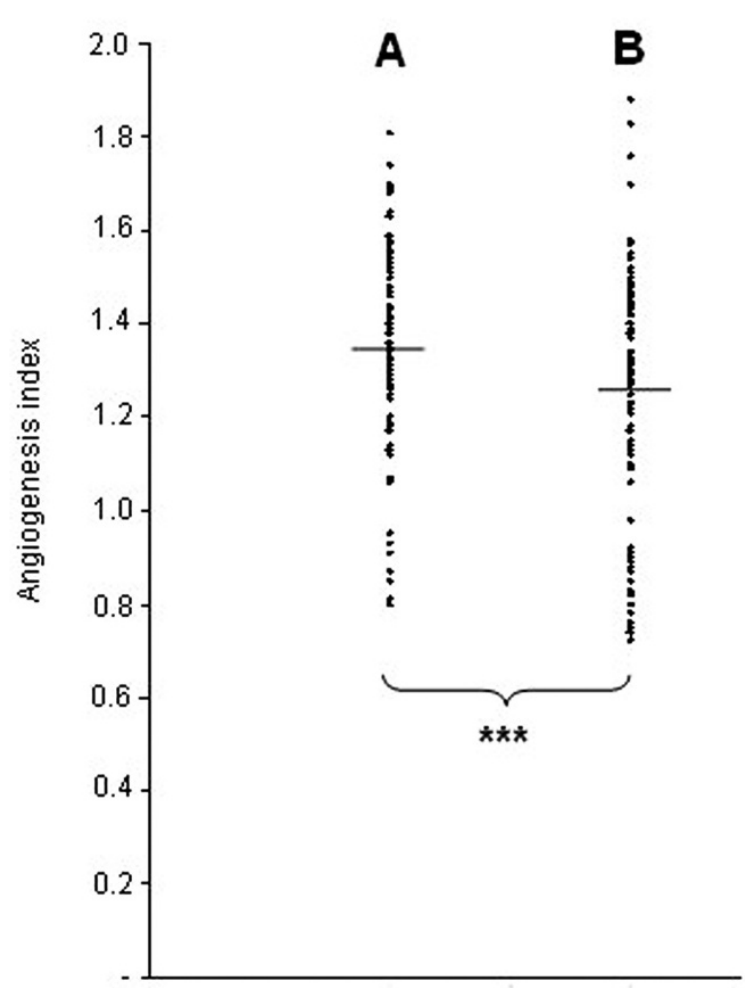

Fig. 3. Angiogenesis index in examined patients with DLco $>80 \%$ of predicted value $(\mathrm{A} ; \mathrm{n}=122)$ compared with those with $\mathrm{DL}_{\mathrm{CO}}<80 \%(\mathrm{~B} ; \mathrm{n}=94)$. The mean values are indicated by horizontal bars; $* * * \mathrm{P}<0.001$ for the difference between the two groups.

Also, the mean angiogenesis index was significantly higher in the group with $\mathrm{DL}_{\mathrm{CO}}>80 \%$ compared with the patients having $\mathrm{DL}_{\mathrm{CO}}<80 \%$ (Fig. 3).

\section{Discussion}

Although the evidence of angiogenesis in the pathogenesis of ILD accumulates, the role of the process during the disease course is unclear. It remains to be explained whether the process intensifies with the increase in fibrosis and whether it can be observed in the early stages of disease. It is also difficult to formulate an unequivocal answer to the question of whether angiogenesis is a component of lung fibrosis development or an element of the lung's defence against the destructive impact of fibrosis. Keane et al [13, 14] have demonstrated increased angiogenic activity in lung tissue of IPF patients and experimental drug-induced pulmonary fibrosis. Sekiya et al [15] have demonstrated that serum VEGF values in patients with sarcoidosis constitute a predictive factor in determining extra-thoracic organ involvements. Navarro et al [7] have observed an increase in the VEGF serum level in EAA patients and a significant decrease in BALF, compared with healthy controls. Tachihara et al [16] have demonstrated in NSIP and IPF patients a decrease in the expression of VEGF mRNA in the alveolar septa associated, with a reduction in the number of capillary tubes via endothelial cell apoptosis that possibly results in alveolar remodelling. However, tests using the in situ hybridization method and im- munohistochemical tests of lung cross-sections for sarcoidosis patients provided evidence of the increased expression of mRNA for VEGF in lung macrophages, epithelial and giant cells as well as the increased production of VEGF by these cells [17]. The above described indicates the complexity and heterogeneity of the ILD group.

The highest proangiogenic activity of sera was observed in granulomatous diseases such as sarcoidosis, allergic alveolitis, and collagen diseases, and also in vasculitis. The sera of patients with diseases linked mainly to pulmonary fibrosis show increased proangiogenic activity, but less intense than in granulomatous diseases and vasculitis. In all our cases, after diagnosis of DIPF, the harmful treatment was stopped and patients were examined in an inactive phase of the disease. It explains why the serum angiogenic activity in patients with DIPF was similar to the activity of sera from healthy controls. This indicates how important the stage and severity of illness are at the moment of the evaluation of angiogenic activity. In earlier research we demonstrated that angiogenic activity in sarcoidosis patients is significantly higher in phase II than in phases I and III [18]. Sera from sarcoidosis patients with extra-pulmonary changes exert a stronger effect on angiogenesis than sera from patients with thoracic changes only [18]. Antoniou et al [19] have demonstrated different angiogenic activity in pulmonary sarcoidosis and IPF.

In contrast to many ILD, sera from scleroderma and PLH patients exert an inhibitory effect on angiogenesis compared with the PBS and healthy controls. Late stages of scleroderma are characterized by the loss of dermal papillae, subepidermal fibrosis, and hypovascularity subunit expression [20]. Our results suggest an increase in angiostatic factors in serum from scleroderma patients. Endostatin has been characterized as a potent inhibitor of VEGF-induced angiogenesis [21]. Mulligan-Kehoe et al [22] have suggested that the angiogenesis seems impaired in scleroderma and this could result from excessive angiostatic factors or disrupted VEGF signaling. Data on neovascularisation in PLH are scarce. Senechal et al [23] have demonstrated that Langerhans cell histiocytosis lesions constituted a site of active inflammation and neoangiogenesis. In contrast, we observed that the sera from pulmonary form of the diseases inhibited angiogenesis. Perhaps angiogenesis only takes part in multifocal Langerhans cell histiocytosis, characterized by a clonal proliferation of cells.

We know little about the relationship between angiogenesis and pulmonary function disturbances in ILD. Simler et al [24] have reported that the serum VEGF level of patients with IPF negatively relates to the change in FVC after 6 months. Recently, a negative correlation between endostatin, forced vital capacity and gas transfer in IPF has been described [25]. A correlation between $\mathrm{DL}_{\mathrm{CO}}$ and serum angiogenic activity is extremely interesting because the diffusing capacity of the lungs depends not only on ventilation and the thickness of the alveolar-vascular barrier, but also on the vascularity of the alveoli. Perhaps, in the early inflammatory phases of ILD stimulation occurs as confirmed by increased angiogenic activity in the serum of 
patients. Neovascularisation in a lung leads to an increase in diffusion gases and an improvement of the lung function. Perhaps, this process plays a pivotal role in controlling the migration of T-cells to the sites of ongoing inflammation, thereby facilitating structural regeneration. During this period, angiogenesis may perform a protective role in the pathogenesis of disease. Newly developed vessels may also easily facilitate the migration of circulating fibrocytes through chemotactic agents and, therefore, may lead to fibrogenesis per se. Renzoni et al [5] have suggested that angiogenesis may occur in the earlier stages of the development of pulmonary fibrosis because of a reduction in the total vascular area and vascular density in IPF patients. Burdick et al [26] have demonstrated that angiogenic activity in the lungs of patients with IPF is significantly decreased.

The fundamental question remains of whether there are too many or too few new vessels in pulmonary fibrosis. We still do not know whether angiogenesis helps or destroys. Perhaps it does both. In certain ILD, there is a process leading to an excessive creation of vessels and in others to insufficient numbers of vessels, thereby leading towards respiratory insufficiency. This hampers an unequivocal definition of whether the objective of ILD treatment should be stimulation or inhibition of neovascularisation. Thalidomide has some clinical effect in sarcoid cases resistant to corticosteroid treatment [9]. Recently, Tabata et al [27] have demonstrated that thalidomide prevents bleomycin-induced pulmonary fibrosis in mice. Recent findings support the notion that therapy directed at either inhibition of angiogenesis or augmentation of angiostatic CXC chemokines may be a novel approach in the treatment of IPF [28]. Angiogenesis that leads to aberrant vascular remodelling is regulated by an opposing balance of angiogenic and angiostatic factors. Continuous work is needed to explain the role of neovascularisation in the pathogenesis of ILD; increasing evidence points to the impact of angiogenesis on the development of the disease.

Sera from ILD patients constitute a source of mediators modulating angiogenesis. In the examined ILD in the present study, the most important functional disturbances were decreases in $\mathrm{DL}_{\mathrm{CO}}$ and static compliance. $\mathrm{DL}_{\mathrm{CO}}$ was related to the angiogenic activity of sera from ILD patients.

Acknowledgements: This work was supported by an internal grant from the Institute of Tuberculosis and Lung Diseases in Warsaw.

Conflicts of interest: No conflicts of interest were declared by the authors in relation to this article.

\section{REFERENCES}

1. Demedts M, Wells AU, Antó JM, Costabel U, Hubbard R, Cullinan P, Slabbynck H, Rizzato G, Poletti V, Verbeken EK, Thomeer MJ, Kokkarinen J, Dalphin JC, Taylor AN. Interstitial lung diseases: an epidemiological overview. Eur Respir J 2001; 18 Suppl 32: 2S-16S.

2. Wells AU, Rubens MB, du Bois RM, Hansell DM. Functional impairment in fibrosing alveolitis: relationship to reversible disease on thin section computed tomography. Eur Respir J 1997; 10(2): 280-5.
3. Wagner EJ, Sánchez J, McClintock JY, Jenkins J, Moldobaeva A. Inflammation and ischemia-induced lung angiogenesis Am J Physiol Lung Cell Mol Physiol 2008; 294(2): 351-7.

4. Strieter RM. Pathogenesis and natural history of usual interstitial pneumonia: the whole story or the last chapter of a long novel. Chest 2005; 1285 Suppl 1: 526S-32S.

5. Renzoni EA, Walsh DA, Salmon M, Wells AU, Sestini P, Nicholson AG, Veeraraghavan S, Bishop AE, Romanska HM, Pantelidis P, Black CM, du Bois RM. Interstitial vascularity in fibrosing alveolitis. Am J Respir Crit Care Med 2003; 167(3): 438-43.

6. Tzouvelekis A, Anevlavis S, Bouros D. Angiogenesis in interstitial lung diseases: a pathogenetic hallmark or a bystander? Respir Res 2006; 7: 82.

7. Navarro C, Ruiz V, Gaxiola M, Carrillo G, Selman M. Angiogenesis in hypersensitivity pneumonitis. Arch Physiol Biochem 2003; 111(4): 365-8.

8. Ebina M, Shimizukawa M, Shibata N, Kimura Y, Suzuki T, Endo M, Sasano H, Kondo T, Nukiwa T. Heterogeneous increase in CD34-positive alveolar capillaries in idiopathic pulmonary fibrosis. Am J Respir Crit Care Med 2004; 169 (11): 1203-8.

9. Carlesimo M, Giustini S, Rossi A, Bonaccorsi P, Calvieri S. Treatment of cutaneous and pulmonary sarcoidosis with thalidomide. J Am Acad Dermatol 1995; 32(5): 8669.

10. Zielonka TM, Demkow U, Zycinska K, Filewska M, Bialas B, Kus J, Radzikowska E, Remiszewski P, Szopinski J, Soszka A, Wardyn KA, Skopinska-Rozewska E. Angiogenic activity of sera from interstitial lung disease patients in relation to clinical and radiological changes. Eur J Clin Med 2009; 14 Suppl 4: 259-64.

11. Quanjer PH, Tammeling GJ, Cotes JE, Pedersen OF, Peslin R, Yernault JC. Lung volumes and forced ventilatory flows. Report of working party, standardization of lung function tests. Eur Respir J 1993; 6(Suppl): 540.

12. Sidky YA, Auerbach R. Lymphocyte-induced angiogenesis: a quantitative and sensitive assay for the graft-versushost reaction. J Exp Med 1975; 141(5): 1084-100.

13. Keane MP, Arenberg DA, Lynch JP 3rd, Whyte RI, Iannettoni MD, Burdick MD, Wilke CA, Morris SB, Glass MC, DiGiovine B, Kunkel SL, Strieter RM. The CXC chemokines, IL-8 and IP-10, regulate angiogenic activity in idiopathic pulmonary fibrosis. J Immunol 1997; 159(3): 1437-43.

14. Keane MP, Belperio JA, Moore TA, Moore BB, Arenberg DA, Smith RE, Burdick MD, Kunkel SL, Strieter RM. Neutralization of the CXC chemokine, macrophage inflammatory protein-2, attenuates bleomycin-induced pulmonary fibrosis. J Immunol 1999; 162(10): 5511-8.

15. Sekiya M, Ohwada A, Miura K, Takahashi S, Fukuchi Y. Serum vascular endothelial growth factor as a possible prognostic indicator in sarcoidosis. Lung 2003; 181(5): 259-65.

16. Tachihara A, Jin E, Matsuoka T, Ghazizadeh M, Yoshino S, Takemura T, Travis WD, Kawanami O. Critical roles of capillary endothelial cells for alveolar remodelling in nonspecific and usual interstitial pneumonias. J Nippon Med Sch 2006; 73(4): 203-13.

17. Tolnay E, Kuhnen C, Voss B, Wiethege T, Müller KM. Expression and localization of vascular endothelial growth factor and its receptor in pulmonary sarcoidosis. Virchows Arch 1998; 432(1): 61-5.

18. Zielonka TM, Demkow U, Bialas B, Filewska M, Zycinska K, Radzikowska E, Szopinski J, Skopinska-Rozewska E. Modulatory effect of sera from sarcoidosis patients on mononuclear cells-induced angiogenesis. J Physiol Pharmacol 2007; 58 Suppl 5: 753-66. 
19. Antoniou KM, Tzouvelekis A, Alexandrakis MG, Sfiridaki K, Tsiligianni I, Rachiotis G, Tzanakis N, Bouros D, Milic-Emili J, Siafakas NM. Different angiogenic activity in pulmonary sarcoidosis and idiopathic pulmonary fibrosis. Chest 2006; 130(4): 982-8.

20. Konttinen YT, Mackiewicz Z, Ruuttila P, Ceponis A, Sukura A, Povilenaite D, Hukkanen M, Virtanen I. Vascular damage and lack of angiogenesis in systemic sclerosis skin. Clin Rheumatol 2003; 22(3): 196-202.

21. Hebbar M, Peyrat JP, Hornez L, Hatron PY, Hachulla E, Devulder B. Increased concentrations of the circulating angiogenesis inhibitor endostatin in patients with systemic sclerosis. Arthritis Rheum 2000; 43(4): 889-93.

22. Mulligan-Kehoe MJ, Simons M. Current concepts in nor$\mathrm{mal}$ and defective angiogenesis: implications for systemic sclerosis. Curr Rheumatol Rep 2007; 9(2): 173-9.

23. Senechal B, Elain G, Jeziorski E, Grondin V, Patey-Mariaud de Serre N, Jaubert F, Beldjord K, Lellouch A, Glorion C, Zerah M, Mary P, Barkaoui M, Emile JF, BocconGibod L, Josset P, Debré M, Fischer A, Donadieu J, Geissmann F. Expansion of regulatory T cells in patients with Langerhans cell histiocytosis. PLoS Med 2007; 4(8): e253.

24. Simler NR, Brenchley PE, Horrocks AW, Greaves SM, Hasleton PS, Egan JJ. Angiogenic cytokines in patients with idiopathic interstitial pneumonia. Thorax 2004; 59(4): 581-5.
25. Richter AG, McKeown S, Rathinam S, Harper L, Rajesh P, McAuley DF, Heljasvaara R, Thickett DR. Soluble endostatin is a novel inhibitor of epithelial repair in idiopathic pulmonary fibrosis. Thorax 2009; 64(8): 156-61.

26. Burdick MD, Murray LA, Keane MP, Xue YY, Zisman DA Belperio JA, Strieter RM. CXCL11 attenuates bleomycin-induced pulmonary fibrosis via inhibition of vascular remodelling. Am J Respir Crit Care Med 2005; 171(3): 261-8.

27. Tabata C, Tabata R, Kadokawa Y, Hisamori S, Takahashi M Mishima M, Nakano T, Kubo H. Thalidomide prevents bleomycin-induced pulmonary fibrosis in mice. J Immunol 2007; 179(1): 708-14.

28. Antoniou KM, Pataka A, Bouros D, Siafakas NM. Pathogenetic pathways and novel pharmacotherapeutic targets in idiopathic pulmonary fibrosis. Pulm Pharmacol Ther 2007; 20(5): 453-61.

Address for correspondence:

Tadeusz Maria Zielonka

Department of Family Medicine

Warsaw Medical University

1A, Banacha St.

02-097 Warsaw

Poland

Phone/fax: +48 223186325

E-mail: tmzielonka@wp.pl 